\title{
The Status Quo, Problems and Countermeasures of Direct Investments to Africa from the Enterprises in Fujian
}

\author{
Chen Zhong Zheng Heming \\ Fuzhou University of International Studies and Trade \\ Fuzhou, Fujian, 350202; \\ Fujian Institute of International Economics and Trade \\ Fuzhou, Fujian, 350003
}

\begin{abstract}
It is an important measure to implement the "going out" strategy for better utilizing two resources and two markets of domestic and international under economic globalization in China, which can promote the optimization and upgrading of China's economic structure and the allocation of resources, and form new advantages in participating and leading international economic cooperation and competition. Developing the international capacity cooperation and accelerating the investment in Africa have become an important part of China's "going out" strategy. Combining with the specific reality of direct investment to Africa from the enterprises in Fujian, the main opportunities and challenges faced by enterprises in expanding investments in Africa are analyzed and the corresponding countermeasures are proposed in the text.
\end{abstract}

Keywords-"Going out" strategy; Direct investment to Africa; Resource allocation

\section{INTRODUCTION}

Under the framework of the China-Africa Cooperation Forum, the grade and level of China-Africa economic and trade cooperation have been continuously improved, and Africa has become an emerging destination for overseas investment from Chinese enterprises and an important overseas engineering contracting market (the projects mainly involve in many fields such as electricity, telecommunications, water conservancy, roads, bridges and port construction etc.). Due to the restriction of its own resources, people in Fujian have always enjoyed a tradition of going abroad, the overseas Chinese from Fujian have spread all over the world and have made important contributions to China's open economy. Under the new circumstances, the enterprises in Fujian have been taking innovative measures and greatly expanding the direct investments to Africa and remarkable results have been achieved.

\section{STATUS QUO AND MAIN CHARACTERISTICS OF DiRECT INVESTMENTS TO AFRICA FROM THE ENTERPRISES IN FUJIAN}

In the early 1990s, Fujian's investments in Africa mainly included government assistance projects. After entering the 21st century, under the framework of the China-Africa Cooperation Forum, the direct investment in Africa from the enterprises in Fujian is showing a rapid growth trend. In recent years, under the guidance of the national "the Belt and Road" strategy and the policy of encouraging carrying out ChinaAfrica capacity cooperation, Fujian has been further strengthening its efforts to expand the market in Africa and actively guiding the enterprises with certain comparative advantages to carry out capacity cooperation in Africa, and the initial results have been achieved. As of the end of 2016, there had 110 (98 entities and 12 branch offices)overseas enterprises and branch offices filed and established by Fujian in Africa and the amount of the filed investments in foreign countries had reached USD 835 million dollars. In general, the investments in Africa from the enterprises in Fujian is characterized by diversified development.

\section{A. Diversification of Investment Types}

At present, Fujian's investments to Africa mainly include four types. The first is the extension and development type of China-aid foreign projects. During the process of participating in the construction of China-aid projects, the enterprises will continue to expand its related businesses. For example, the participation of China Wu Yi Co., Ltd. in the construction of China-aid projects in Africa has promoted the rapid development of direct investment in Africa and the exports of its required raw materials and other products such as accessories, machine tools and decoration materials etc. The second is the market development type. Fujian's commodities have comparative advantages, while the commodities are lacked in African countries generally and the African market has a large capacity. For example, Putian Powerland, Fujian Uptop, Jinjiang Yuzhongniao Umbrella Co., Ltd. and many other Fujian foreign trade enterprises have set up their trade marketing networks in Africa, which are close to the market terminals and have promoted and expanded the exports of 
products and services. The third is the resource development type. Fujian Province is a small resource province with extremely scarce resources, and at present, it is facing the industrial structure transformation and upgrading, thus, it urgently needs a large number of natural resources and primary products, while there are exceedingly rich resources in Africa, and it can provide strong support for the import of resources to Fujian Province. Africa is rich in mineral resources, the proven 150 underground mineral resources in the world are stored in Africa, among which, the reserves of platinum, manganese, chromium, ruthenium and niobium account for approximately $80 \%$ in the world's total reserves, the reserves of the mineral resources such as phosphate, gold, diamond, germanium, cobalt and vanadium etc.account for half of the world's total reserves, and there are also abundant petroleum, iron, copper and other resources. The mineral mining is an important cooperative project. For example, Hongdong Fishery Project in Mauritania and the Gold and Copper Mine developed by the Huajin Group in Zimbabwe. The fourth is the capacity cooperation type. The investments focus on the traditional advantageous industries in Fujian such as shoes and hats, clothing, iron and steel, stone processing and motors, and the direct investments in Africa [1] from the enterprises in Fujian are always expanded by means of overseas processing trade.

\section{B. Wide Distribution of Investment Areas}

As of the end of 2016, the filed and registered investment projects in Africa from Fujian were distributed in 35 countries of eastern, western, southern, northern and central Africa, and the amount of the filed investments in foreign countries reached USD 835 million dollars. Among them, there were 17 investment enterprises in South Africa, 16 in Egypt, 8 in Namibia, 5 in Algeria, 4 in Kenya and 4 in Mauritania. And the investments in the above 6 African countries account for $58.9 \%$ of the total investment projects in Africa from Fujian, which is mainly due to the large differences in the economic foundations of African countries and the relatively advanced of southern Africa.

\section{Wide Range of Investment Areas}

The diversified investment patterns of Fujian enterprises' direct investment in Africa has been initially formed. The areas of Fujian's investment in Africa is very extensive, which have been gradually developed from the establishment of trade companies overseas initially into the investments in multiple fields such as mining industry, marine fishery, real estate development, project contracting, comprehensive agricultural development, textile and clothing, shoes, stone, wood, electronics, food, plastics products, ceramic building materials, iron and steel metallurgy, electrical appliance production and processing, engineering equipment rental.

\section{Diversification of Investment Subjects}

The structure of subjects have been further optimized. In the initial stage of implementing the "going out" strategy, the overseas investment enterprises were mainly state-owned enterprises. In addition to state-owned enterprises such as Fujian Wu Yi Co., Ltd., Fujian Construction Engineering Group Co., Ltd., Fujian Overseas Chinese Enterprise, XGMA, Putian International Cooperation Company, Sanming Calcium Carbonate Company, in recent years, many private enterprises have been gradually developed into intermediate forces for Fujian's investment in Africa by virtue of advantageous conditions such as clear property rights and flexible institutional mechanisms. Among the filed Fujian enterprises participating in investments in Africa, more than $85 \%$ of the investment subjects are private enterprises, and private enterprises have been gradually developed into new forces for Fujian's investments in foreign countries.

\section{OPPORTUNITIES AND CHALLENGES FOR EXPANDING THE INVESTMENTS IN AFRICA}

\section{A. Opportunities}

The development strategies of China and Africa are highly consistent. China is the largest developing country, Africa is the most concentrated continent of developing countries, China and Africa have always been the community with a common future. At present, African countries are generally looking forward to accelerating the process of industrialization and agricultural modernization and are committed to promoting the skill development and changes in the business environment, achieving economic independence and independent sustainable development. China has actively implemented the economic restructuring and industrial upgrading, its industrial scale, technological level and international competitiveness have been greatly increased and the relative development advantages such as capital, technology, talent, equipment and high-quality surplus capacity have been accumulated. Under the slow recovery and diversified development of the world economy, and the pattern of international investment and trade and the profound adjustment of multilateral investment and trade rules, China's government has issued the Vision and Actions on Jointly Building Silk Road Economic Belt and 21st-Century Maritime Silk Road, which is formulated to promote the pragmatic cooperation and build the community of interests comprehensively through "policy communication, infrastructure interconnection, smooth trade, financing and popular support", which provides an important opportunity for deepening China-Africa multi-layered economic and trade cooperation [2]. 
There is a sound economic cooperation mechanism between China and Africa. In 2015, the Johannesburg Summit of the China-Africa Cooperation Forum established "Ten China-Africa Cooperation Plans" including the China-Africa Industrialization Cooperation Plan, China-Africa Agricultural Modernization Cooperation Plan and China-Africa Infrastructure Cooperation Plan, in order to promote the industrialization process and the comprehensive development of economic social in Africa. In May 2015, Premier Li Keqiang visited four African countries and proposed the "461 Cooperation Framework." Under the background, the prospect for Fujian enterprises to expand the African market will be even wider. The work mechanisms such as the Economic and Trade Joint Committee between China and some African countries are playing a positive role in promoting the development of bilateral economic and trade cooperation.

The economies of Fujian and Africa are highly complementary. There is a vast territory, a large population and abundant resources in Africa. However, at present, the economy in Africa is still relatively backward, all industries still need to be developed, and the capital, technology, and management experience are lacked. A large number of products from industrial raw materials and production equipment to people's livelihood products should be exported in the African market, especially the demands for the commodities such as steels, textiles, clothing, shoes, building materials, bags, machinery and electronics are huge, and these products are Fujian's dominant commodities. With the rapid and comprehensive development of China-Africa economic and trade cooperation, Africa has become China's secondlargest overseas project contracting market and emerging investment destination. The private enterprises in Fujian have relatively abundant funds and technical and managerial experience suitable for the stage of economic development in Africa. The resource endowments between Fujian and Africa are complementary with each other. There are 54 countries in Africa, covering a population of 1 billion, the territory is vast, the economic growth is rapid, and the natural resources and mineral resources are abundant. Africa has comparative advantages in terms of labor, land and raw materials etc. and also have rich mineral resources, it can provide an important development space for Fujian to achieve industrial transfer, eliminate excess production capacity and promote the foreign trade transformation and upgrading. For example, the cost of the element resources such as labor and land in Ethiopia and Tanzania are very low, and these African countries have preferential tariff advantages for exports to the EU, the United States and Africa; there are abundant mineral resources in Tanzania and South Africa such as coal, iron, natural gas, precious stones, etc.; South Africa also has significant advantages in fields such as automobile manufacturing, machinery manufacturing, military technology, logistics and ore processing [2].

\section{B. Risks and Challenges}

Restricted by the level of regional economic and social development, there are still some restrictive factors in the economic cooperation between Fujian and African countries at present. In general, the risk of overseas investment in Africa from the enterprises in Fujian is relatively high, which is mainly restricted by factors such as social instability in African countries, imperfect laws and regulations, poor security situation, low labor quality and low operation efficiency of administrative bodies. For example, Africa is a multi-ethnic settlement where the ethnic conflicts are frequent and the political situations are turbulent chronically; the overall labor quality in Africa is low, the marketization level is low in African countries, and the business environment is relatively poor, which severely restrict the economic and social development in Africa.

In addition, there are also restriction factors from Fujian companies themselves.

The competitiveness of the enterprise is not strong enough. The investment subjects in Africa from Fujian are dominated by small and medium-sized private enterprises, many of them invest in Africa as a natural person, the scale of the overseas entity is generally small, most of them rely on low cost and low prices to survive, and the professional technicians and international management talents are insufficient seriously, which lead to the technical innovation capability and operation and management capability of the investment enterprises in Africa weak.

The financing channel of the enterprise is not smooth. The scale of overseas investment enterprises from Fujian to Africa is generally small, the credit rating of the project is relatively low, and the financing capacity of the enterprise is also weak. In addition, the traditional guarantee business provided by the banks in China are difficult to meet the financing demands of the enterprise, and at present, only the banks such as Bank of China and Export-Import Bank of China can provide special loans or syndicated loans, while the services provided by overseas branches of Chinese banks also rely on traditional businesses, and there have been no branches set in many countries so that the effective financial support cannot be provided for Fujian's "going out” enterprises.

There are obstacles in the integration of the enterprise with African culture. There are numerous ethnic tribes in Africa and their customary etiquettes are different. Fujian's "going out" enterprises should respect the traditional local customs when expanding their investment in Africa and promote integration with local African culture. The "going out" enterprises must also actively perform corporate social responsibility, attract the local people to employment and protect the local ecological environment. 


\section{SUGGESTIONS For PROMOTING THE DiRECT INVESTMENTS TO AFRICA FROM THE ENTERPRISES IN FUJIAN}

\section{A. Promote competitive Industries to go out}

Fujian has certain comparative advantages in the industries such as light textile processing, machinery and electronics, food, agriculture, forestry and fishery, and engineering construction. The products from these industries occupy a certain market share in Africa currently. Encouraging such enterprises to set up trade companies or found factories directly abroad is conductive for the enterprises to better understanding the market and expanding the exports. The labor-intensive industries such as textiles, clothing and shoes also have comparative advantages, and a group of enterprises with international competitiveness should be guided and supported to establish production and processing bases in Ethiopia and other African countries with abundant labor force and relatively stable political situation in order to appropriately transfer the production and processing links and the surplus production capacity, make full use of domestic and foreign production factors, achieve the diversification of the place of origin, drive exports of complete equipment and semi-finished products in Fujian and avoid trade barriers.

\section{B. Promote Resource-Based Enterprises to go out}

In 1997, China proposed the "going out" strategy of making full use of the "two resources and two markets", and the investments in foreign countries' resources and energies were blown out. With the increasingly prominent contradiction between the supply and demand of mineral resources and accelerating internationalization process, it has been an irresistible trend for resource-based enterprises to "go out" and develop overseas resources, the enterprises should be actively supported and encouraged to "go out" and open up the international market, while the financing, credit guarantees, foreign exchange management and other supporting policies should be provided for the enterprises during investment in foreign countries and transnational operations. In the international resource cooperation, in addition to paying attention to funds, personnel and technology, the "going out" resource-based enterprises should also pay attention to corporate image and reputation and actively perform corporate social responsibilities such as environmental responsibility, competition responsibility and labor relations. The "going out " and investment in foreign countries should be accelerated, including forms of cooperative development, merger and acquisition or joint stock [3].

\section{Promote Capacity Cooperation Between Fujian and Africa}

The resource-intensive and labor-intensive industries in Fujian, such as light industry, textiles, electromechanical, stone, ceramic tile, etc. are industries with comparative advantages and industries with excess production capacity and the operation of many enterprises have become increasingly difficult. The resource space and market space are very large in Africa, the development space for Fujian enterprises can be opened up, their international operation capabilities can be enhanced, the industrial transformation and upgrading in Fujian can be promoted and the exports of device and equipment to Africa can be promoted through promoting the enterprises with excess production capacity to "go out" and optimizing the resource allocation.

\section{Promote Enterprises to Develop Agricultural Cooperation and Development in Africa}

In Africa, the land resources are rich, the natural conditions are superior and it has a good foundation for the development of agriculture. However, due to the fact that Africa's agricultural economy is mainly by planting, the agricultural production technologies such as primary crop processing, deep crop processing and storage technologies are outdated, the agricultural added value is low, the labor productivity is lower, and the ability to withstand natural disasters is weaker, the food shortage situation in Africa is still quite severe, and the food cannot be self-sufficient in $80 \%$ of African countries. Among the 54 independent countries in Africa, 20 countries are deeply in the food crisis, and the number of hungry people in subSaharan Africa is 265 million, and the political instability is caused in many African countries due to food problems. The severe impact of the global food crisis can be resisted to a certain extent through promoting enterprises to carry out agricultural cooperation and development in Africa. Fujian has accumulated many successful technologies and experience in agricultural production and deep processing of agricultural products, and the qualified and large planting and private enterprises should be actively encouraged to invest in agriculture and deep processing of agricultural products in Africa; through lease, contract and purchase of local land, etc., the agricultural production base can be established so as to drive the exports of Fujian's agricultural production technologies and agricultural machinery and the comprehensive development of African agriculture can be promoted through the demonstration effect.

\section{E. Promote Enterprises to Establish African Industrial parks}

The industrial parks or economic and trade parks can gather scarce elements and give play to scale benefits. If the enterprises invest in industrial parks, they can also enjoy better guarantees in terms of labor, water, electricity, customs clearance and tax preference. The powerful enterprises such as Wu Yi Co., Ltd. should be actively encouraged to "go out" and set up industrial parks overseas. Through the construction of the park, it cannot only promote the export of Fujian products, but can also guide the local enterprises to enter the park and achieve agglomeration development, transfer surplus production capacity and expand the sales of "Fujian goods" in Africa. 
In Africa, the capital, technology, talent and other factors are still in short supply, and the advantageous resources within a limited scope can be concentrated through the parks, the economic development can be promoted and the development of industrial parks can be promoted. Fujian enterprises should also support the development of the industrial parks in African countries, expand the cooperation scale, improve the cooperation quality, contribute their own efforts to achieving industrialization in Africa and build a new platform for cooperation between China and Africa.

\section{CONCLUSION}

Fujian should further strengthen its investment to Africa in accordance with the national "the Belt and Road" strategy and the policy of encouraging China-Africa production capacity cooperation, and a series of countermeasures and suggestions for direct investments to Africa have been concluded through researching the opportunities and challenges of investments in Africa, including encouraging the advantageous enterprises to go out, encouraging the enterprises to go out and carry out the capacity cooperation, etc.

\section{ACKNOWLEDGMENT}

About the author: Chen Zhong, Director and Professor of the Open Economy and Trade Research Center of Fuzhou University of Foreign Studies and Trade. Research direction: International trade. Zheng Heming, assistant researcher and doctor of Fujian Institute of Foreign Economics and Trade, research direction: corporate finance and foreign investment.

\section{REFERENCES}

[1] Zhang Guangrong: Theoretical Interpretation of China to Carry out Overseas Investment in Resources and Energy [J], International Trade, Issue 8, 2010

[2] Zhang Guosheng: "Going Out" of Energy Resources Industry: International Experience and Policy Suggestions [J], International Economic Cooperation, Issue 4, 2014.

[3] Feng Xingyan: The Strategic Choice of China-Africa Investment Cooperation in Overseas Economic and Trade Cooperation Regions [J], International Economic Cooperation, Issue 4, 2011. 